American Journal of Biochemistry and Biotechnology 8 (1): 14-20, 2012

ISSN 1553-3468

(C) 2012 Fakruddin and Chowdhury, This open access article is distributed under a Creative Commons Attribution

(CC-BY) 3.0 license

\title{
Pyrosequencing-An Alternative to Traditional Sanger Sequencing
}

\author{
Fakruddin and Abhijit Chowdhury \\ Institute of Food Science and Technology (IFST), \\ Bangladesh Council of Scientific and Industrial Research (BCSIR), Dhaka, Bangladesh
}

\begin{abstract}
Problem statement: Pyrosequencing has the potential to rapidly and reliably sequence DNA taking advantages over traditional Sanger di-deoxy sequencing approach. Approach: A comprehensive review of the literature on the principles, applications, challenges and prospects of pyrosequencing was performed. Results: Pyrosequencing was a DNA sequencing technology based on the sequencing-by-synthesis principle. It employs a series of four enzymes to accurately detect nucleic acid sequences during the synthesis. Pyrosequencing had the potential advantages of accuracy, flexibility, parallel processing and could be easily automated. The technique dispenses with the need for labeled primers, labeled nucleotides and gel-electrophoresis. Pyrosequencing had opened up new possibilities for performing sequence-based DNA analysis. The method had been proven highly suitable for single nucleotide polymorphism analysis and sequencing of short stretches of DNA. Pyrosequencing had been successful for both confirmatory sequencing and de novo sequencing. By increasing the read length to higher scores and by shortening the sequence reaction time per base calling, pyrosequencing may take over many broad areas of DNA sequencing applications as the trend was directed to analysis of fewer amounts of specimens and large-scale settings, with higher throughput and lower cost. Conclusion/Recommendations: The Competitiveness of pyrosequencing with other sequencing methods can be improved in future.
\end{abstract}

Key words: Pyrosequencing, Sanger sequencing, alternative, advantage

\section{INTRODUCTION}

Genome sequencing has provided us with powerful insights into the genetic make-up of the microbial world and has spearheaded a host of revolutionary technologies, such as microarrays and proteomics that have transformed the field of microbiological research. Sequence determination is most commonly performed using di-deoxy chain termination technology (Ronaghi, 2001). The chain termination sequencing method, also known as Sanger sequencing, was developed by Frederick Sanger and colleagues (Sanger et al., 1977), has been the most widely used sequencing method since its advent in 1977 and still is in use after more than 29 years. Despite all the advantages, there are limitations in this method, which could be complemented with other techniques (Gharizadeh et al., 2007). Recently, pyrosequencing has emerged as a new sequencing methodology (Ronaghi, 2001).

Limitations of Sanger Sequencing Method: The Sanger sequencing method (Sanger et al., 1977) has been the workhorse technology for DNA sequencing since it's invent. Though Sanger method is still considered by the research community as the gold standard for sequencing, it has several limitations such as- (1) A great limitation of the Sanger sequencing method for larger sequence output is the need for gels or polymers used as sieving separation media for the fluorescently labeled DNA fragments. (2) Relatively low number of samples could be analyzed in parallel. (3) Total automation of the sample preparation methods is difficult. (4) DNA fragments need to be cloned into bacteria for larger sequences. (5) High cost of sequencing. (6) Sequencing errors.6. Level of sensitivity (generally estimated at 10-20\%) insufficient for detection of clinically relevant low-level mutant alleles or organisms. (7) cis or trans orientation of heterozygous positions may be difficult to resolve during data analysis. (8) Not readily scalable to achieve a throughput capable of efficiently analyzing complex diploid genomes at low cost. (9) de novo genome assembly is difficult (Ansorge, 2009; Hall, 2007).

Alternatives of Sanger Sequencing: Many research groups around the world have made effort to develop alternative principles of DNA sequencing. Three methods that hold great promise are sequencing by

Corresponding Author: Md. Fakruddin, Institute of Food Science and Technology (IFST), Bangladesh Council of Scientific and Industrial Research (BCSIR), Dhaka, Bangladesh 
hybridization (Bains and Smith, 1988; Drmanac et al., 1989; Khrapko et al., 1989; Southern, 1989) parallel signature sequencing based on ligation and cleavage (Brenner et al., 2000) and pyrosequencing (Ronaghi et al., 1996; Ronaghi et al., 1998).

Pyrosequencing: Pyrosequencing technology is a novel DNA sequencing technology, developed at the Royal Institute of Technology (KTH) and is the first alternative to the conventional Sanger method for de novo DNA sequencing. This method relies on the luminometric detection of pyrophosphate that is released during primer-directed DNA polymerase catalyzed nucleotide incorporation. It is suited for DNA sequencing of up to one hundred bases and it offers a number of unique advantages (Gharizadeh, 2003). This technique is a widely applicable, alternative approach for the detailed characterization of nucleic acids. Pyrosequencing has potential advantages of accuracy, flexibility, parallel processing and can be easily automated. Furthermore, the technique avoids the need for labeled primers, labeled nucleotides and gelelectrophoresis. Pyrosequencing has been successful for both confirmatory sequencing and de novo sequencing (Ronaghi, 2000).

Principles of Pyrosequencing: Pyrosequencing technique is based on sequencing-by-synthesis principle (Hyman, 1988; Melamede, 1985) and on the detection of released Pyrophosphate (PPi) during DNA synthesis (Ronaghi, 2001). It employs a series of four enzymes to accurately detect nucleic acid sequences during the synthesis. In Pyrosequencing (Nyren and Skarpnack, 2001) the sequencing primer is hybridized to a single-stranded DNA biotinlabeled template and mixed with the enzymes; DNA polymerase, ATP sulfurylase, luciferase and apyrase and the substrates adenosine 5' phosphosulfate (APS) and luciferin (Gharizadeh et al., 2007).

Cycles of four deoxynucleotide triphosphates (dNTPs) are separately added to the reaction mixture iteratively. The cascade starts with a nucleic acid polymerization reaction in which inorganic PPi is released as a result of nucleotide incorporation by polymerase. Each nucleotide incorporation event is followed by release of inorganic Pyrophosphate (PPi) in a quantity equimolar to the amount of incorporated nucleotide. Subsequently the released PPi is quantitatively converted to ATP by ATP sulfurylase in the presence of APS. The generated ATP drives the luciferase-mediated conversion of luciferin to oxyluciferin, producing visible light in amounts that are proportional to the amount of ATPs. The light in the luciferase-catalyzed reaction with a maximum of 560 nanometer wavelength is then detected by a photon detection device such as A Charge Coupled Device (CCD) camera or photomultiplier. Apyrase is a nucleotide-degrading enzyme, which continuously degrades ATP and non-incorporated dNTPs in the reaction mixture. There is a certain time interval (usually $65 \mathrm{sec}$ ) between each nucleotide dispensation to allow complete degradation. For this reason, dNTP addition is performed one at a time (Gharizadeh et al., 2007). Because the added nucleotide is known, the sequence of the template can be determined (Ronaghi, 2001). A schematic representation of pyrosequencing is shown in Fig. 1.

The generated light is observed as a peak signal in the pyrogram (corresponding to electropherogram in dideoxy sequencing) proportional to the number of nucleotides incorporated (a triple dGTP incorporation generates a triple higher peak) (Gharizadeh et al., 2007). During this synthesis process, the DNA strand is extended by complementary nucleotides and the DNA sequence is demonstrated by the pyrogram on a screen.

The slope of the ascending curve in a pyrogram displays the activities of DNA polymerase and ATP sulfurylase, the height of the signal shows the activity of luciferase and the slope of the descending curve demonstrates the nucleotide degradation (Gharizadeh, 2003). Base-callings are performed with integrated software, which has many features for related SNP and sequencing analysis (Gharizadeh et al., 2007). The overall reaction from polymerization to light detection takes place within 3-4 sec at room temperature (Ronaghi, 2001). ATP sulfurylase converts PPi to ATP in approximately $1.5 \mathrm{sec}$ and the generation of light by luciferase takes place in less than $0.2 \mathrm{sec}$ (Nyren and Lundin, 1985). Standard pyrosequencing uses the Klenow fragment of Escherichia coli DNA Pol I (Benkovic and Cameron, 1995).

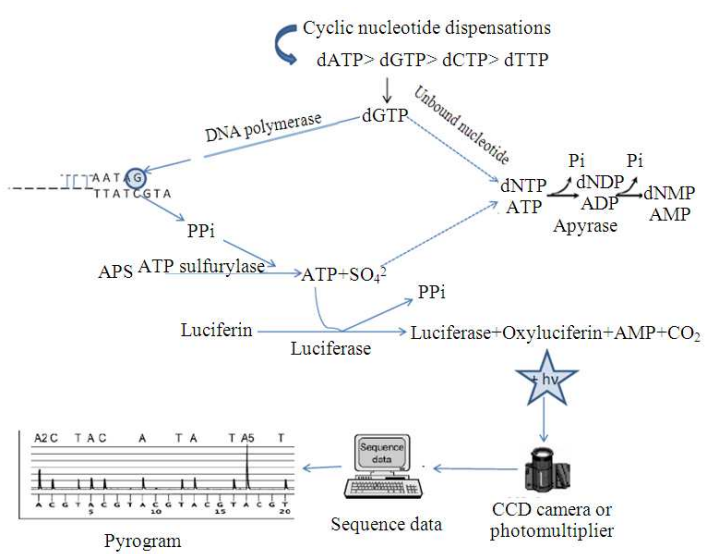

Fig. 1: Schematic representation of pyrosequencing 
The ATP sulfurylase used in pyrosequencing is a recombinant version from the yeast Saccharomyces cerevisiae (Karamohamed et al., 1999) and the luciferase is from the American firefly Photinus pyralis (Ronaghi, 1999). The apyrase is from Solanum tuberosum (Pimpernel variety) (Espinosa et al., 2003; Nourizad et al., 2003).

Advantages of pyrosequencing: Pyrosequencing has emerged as an alternative method of sequencing. Although it has read-length limitations compared with di-deoxy sequencing, it is a fast method with real-time read-out that is highly suitable for sequencing short stretches of DNA (Gharizadeh et al., 2007).

Pyrosequencing employs co-operativity of several enzymes to monitor DNA synthesis. Parameters such as stability, fidelity, specificity, sensitivity, KM and kcat are mandatory for the optimal performance of the enzymes used in the sequencing reaction. The kinetics of the enzymes can be studied in realtime (Gharizadeh et al., 2003c).

Unlike Sanger sequencing, which lays a reading gap of roughly 20-30 bases from the sequencing primer, pyrosequencing can generate sequence signals immediately downstream of the primer. As sequencing starts with the first base next to the annealed primer, making primer design becomes more flexible in this method. Sample and single-strand DNA preparation process is also relatively rapid (about $15 \mathrm{~min}$ ), while sample preparation takes approximately $4 \mathrm{~h}$ for Sanger sequencing (60 min for PCR cleanup, 3-4 h for cyclic amplification and $15 \mathrm{~m}$ for dye cleanup). The reagent costs are considerably lower for sequencing short stretches of DNA compared to currently available methods (Gharizadeh et al., 2007).

The pyrosequencing technology has many unique advantages over other DNA sequencing technologies. One advantage is that the order of nucleotide dispensation can be easily programmed and alterations in the pyrogram pattern reveal mutations, deletions and insertions. Moreover, this technique is carried out in real-time, as nucleotide incorporations and base callings can be observed continuously for each sample. In addition, the Pyrosequencing method can be automated for large-scale screenings (Gharizadeh et al., 2003c).

Industrialization of pyrosequencing: The availability of an automated system for liquid-phase pyrosequencing (PSQ 96 system, http://www.pyrosequencing. com) has allowed the technique to be adapted for high-throughput analyses (Ronaghi, 2001). Pyrosequencing is now being applied in microfluidic format commercially by 454 Life Sciences Corporation (Branford, CT, USA). The microfluidic pyroseqeuncing has been integrated with emulsion PCR and DNA sequencing assembly software. The new platform has the ca pacity to sequence up to 300,000 samples and generate up to 2040 million bases at an accuracy of $99 \%$ per $4 \mathrm{~h}$ sequencing run (Gharizadeh et al., 2007).

Application of pyrosequencing: Pyrosequencing has opened up new possibilities for performing sequencebased DNA analysis (Ronaghi, 2001). Pyrosequencing is well suited for de novo sequencing and resequencing (Ronaghi, 2001). Currently, pyrosequencing method is broadly being used in many applications such as Single Nucleotide Polymorphism (SNP) genotyping (Ahmadian et al., 2000a; Nordstrom et al., 2000; Milan et al., 2000), identification of bacteria (Gharizadeh, 2003; Grahn et al., 2003; Jonasson et al., 2002), fungal (Gharizadeh et al., 2005; Trama et al., 2005) and viral typing (Gharizadeh et al., 2001; 2003; 2005; Adelson et al., 2005). Moreover, the method has demonstrated the ability to determine difficult secondary structures (Ronaghi, 2001) and perform mutation detection (Ahmadian et al., 2000b; Garcia et al., 2000), DNA methylation analysis (Neve et al., 2002; Uhlmann et al., 2002), multiplex sequencing (Gharizadeh et al., 2003a; 2006) (Gharizadeh et al., 2003b; Gharizadeh et al., 2006), tag sequencing of cDNA library (Nordstrom et al., 2001) and clone checking (Nourizad et al., 2003). Another highly significant application is whole genome sequencing (Margulies et al., 2005). Some of the potential applications of pyrosequencing have been described in Table 1 .

\begin{tabular}{|c|c|c|c|}
\hline Organism & Application & Target & Reference \\
\hline Eubacteria & $\begin{array}{l}\text { Profiling and } \\
\text { Identification }\end{array}$ & $\begin{array}{l}\text { In stomachs of } \\
\text { Mongolian without } \\
\text { gerbils with or } \\
\text { Helicobacter pylori }\end{array}$ & (Sun et al., 2003) \\
\hline Mixed bacteria & Identification & $\begin{array}{l}\text { In DNA-contaminated } \\
\text { PCR amplifications } \\
\text { of } 16 S \text { DNA variable } \\
\text { VR1 and VR3 regions }\end{array}$ & (Grahn et al., 2003) \\
\hline General bacteria & $\begin{array}{l}\text { Classification, } \\
\text { Identification } \\
\text { and subtyping }\end{array}$ & $\begin{array}{l}\text { Analysis of } 16 \mathrm{~S} \\
\text { rDNA fragments }\end{array}$ & (Jonasson et al., 2002) \\
\hline Lactobacilli & Identification & $\begin{array}{l}\text { DNA VRs within } \\
\text { colonies collected from } \\
\text { normal vaginal fluid }\end{array}$ & (Tarnberg et al., 2002) \\
\hline Helicobacter pylori & $\begin{array}{l}\text { Profiling, } \\
\text { Identification } \\
\text { and subtyping } \\
\text { Identification }\end{array}$ & $\begin{array}{l}\text { NudA protein } \\
\text { 16S DNA VR } 1 \text { and VR3 }\end{array}$ & $\begin{array}{l}\text { (Lundin } \text { et al., 2003) } \\
\text { (Sun } \text { et al., 2003; } \\
\text { Monstein } \text { et al., 2001) }\end{array}$ \\
\hline $\begin{array}{l}\text { Listeria } \\
\text { Monocytogenes }\end{array}$ & Grouping & $\begin{array}{l}\text { Single Nucleotide } \\
\text { Polymorphisms (SNP) } \\
\text { in the inlB gene }\end{array}$ & (Unnerstad et al., 2001) \\
\hline Papillomavirus & Typing & $\begin{array}{l}\text { Human Papilloma Virus } \\
\text { (HPV) }\end{array}$ & (Gharizadeh et al., 2001) \\
\hline $\begin{array}{l}\text { Human } \\
\text { Immunodeficiency } \\
\text { Virus (HIV) }\end{array}$ & Monitoring & $\begin{array}{l}\text { Resistance to HIV type } 1 \\
\text { Protease Inhibitors (PI) }\end{array}$ & (O’Meara et al., 2001) \\
\hline Viruses & Quantitative & Estimation of viral fitness & (Lahser et al., 2003) \\
\hline
\end{tabular}


Challenges of pyrosequencing: Pyrosequencing was earlier limited to sequencing of short stretches of DNA, due to the inhibition of apyrase. The natural dATP was a substrate for luciferase, resulting in false sequence signals dATP was substituted by dATP- $\alpha-\mathrm{S}$ (Ronaghi et $a l ., 1996)$. By introducing the dATP- $\alpha-\mathrm{S}$ Sp isomer, substantial longer reads were achieved. This improvement had a major impact on pyrosequencing read length and allowed sequencing of up to one hundred bases (Gharizadeh et al., 2002) and opened up avenues for numerous applications (Gharizadeh et al., 2007).

Homopolymer Ts (more than 3-4) are a challenge in Pyrosequencing. Homopolymer string (mainly homopolymeric $\mathrm{T}$ ) regions can influence synchronized extension and synthesis of the DNA strand causing nonuniform sequence peak heights, affecting the readlength and possibly causing sequence errors. By employing Sequenase (Gharizadeh et al., 2004), an exonuclease deficient T7 DNA polymerase, the poly-T homopolymer string reads were significantly improved by generation of significantly more synchronized sequence and uniform signal peaks after homopolymeric T regions (Gharizadeh et al., 2007).

An important factor in pyrosequencing is primer design for PCR and sequencing. Sequencing primers should be checked for self-looping, primer-dimer (primer-primer hybridizations) and cross-hybridization (when more than one sequencing primer is used). (Gharizadeh et al., 2007).

An inherent problem with the described method is de novo sequencing of polymorphic regions in heterozygous DNA material (Ronaghi, 2001).

Another inherent problem is the difficulty in determining the number of incorporated nucleotides in homopolymeric regions, due to the nonlinear light response following incorporation of more than 5-6 identical nucleotides (Ronaghi, 2001).

Prospects of pyrosequencing: Future applications require more robust and efficient DNA sequencing techniques for sequence determination. The Pyrosequencing method has already shown evidence of high accuracy in DNA sequencing and analysis of polymorphic DNA fragments in many clinical and research settings. It is a relatively straightforward and user-friendly method possessing unique methodological characteristics and this technique is currently being used in multidisciplinary fields in academic, clinical and industrial settings. By increasing the read length to higher scores and by shortening the sequence reaction time per base calling, pyrosequencing may take over many broad areas of DNA sequencing applications as the trend is directed to analysis of fewer amounts of specimens and large-scale settings, with higher throughput and lower cost (Gharizadeh et al., 2007).
Pyrosequencing has shown excellent accuracy in analysis of polymorphic DNA fragments. This technology has also been used for quantification of allelic frequency in populations. Pyrosequencing will have a large impact in that area because a large number of samples can be pooled in one pyrosequencing reaction. A high throughput version of this technology can potentially be used for resequencing of genomes. Pyrosequencing technology is relatively new and there lies ample room for versatile developments in both chemistry and instrumentation. This technology is already time-and cost-competitive as compared to the most conventional sequencing methods. Work is underway to further improve the chemistry, to measure the sequencing efficiency at elevated temperatures and to run the reaction in miniaturized formats (Ronaghi, 2001).

\section{CONCLUSION}

Pyrosequencing method is the first alternative to the conventional Sanger di-deoxy method for de novo DNA sequencing. There are still opportunities for further breakthroughs in this area as only very few research groups have focused on this method. In future, pyrosequencing technology is expected to achieve longer read length, to reduce the sequencing time frame, to decrease the sample quantity and to make further improvements in automation.

\section{REFERENCES}

Adelson, M.E., M. Feola, J. Trama, R.C. Tilton and E. Mordechai, 2005. Simultaneous detection of herpes simplex virus types 1 and 2 by real-time PCR and pyrosequencing. J. Clin. Virol., 33: 2534. PMID: 15797362

Ahmadian, A., B. Gharizadeh, A.C. Gustafsson, F. Sterky and P. Nyren et al., 2000a. Single-nucleotide polymorphism analysis by pyrosequencing. Anal. Biochem., 280: 103-110. PMID: 10805527

Ahmadian, A., J. Lundeberg, P. Nyren, M. Uhlen and M. Ronaghi, 2000b. Analysis of the p53 tumor suppressor gene by pyrosequencing. Biotechniques, 28: 140-147. PMID: 10649785

Ansorge, W.J., 2009. Next-generation DNA sequencing Techniques. New Biotechnol., 25: 195-203. PMID: 19429539

Bains, W and G.C. Smith, 1988. A novel method for nucleic acid sequence determination. J. Theoretical Biol., 135: 303-307. DOI: 10.1016/S00225193(88)80246-7 
Benkovic, S.J. and C.E. Cameron, 1995. Kinetic analysis of nucleotide incorporation and misincorporation by Klenow fragment of Escherichia coli DNA polymerase I. Methods Enzymol., 262: 257-269. DOI: 10.1016/00766879(95)62022-2

Brenner, S., S.R. Williams, E.H. Vermaas, T. Storck and K. Moon et al., 2000. In vitro cloning of complex mixtures of DNA on microbeads: Physical separation of differentially expressed cDNAs. Proc. Natl. Acad. Sci., 97: 1665-1670. DOI: 10.1073/pnas.97.4.1665

Drmanac, R., I. Labat, I. Brukner and R. Crkvenjakov, 1989. Sequencing of megabase plus DNA by hybridization: Theory of the method. Genomics, 4 : 114-128. Doi: 10.1016/0888-7543(89)90290-5

Espinosa, V., A.M. Kettlun, A. Zanocco, E. Cardemil and M.A. Valenzuela, 2003. Differences in nucleotide-binding site of isoapyrases deduced from tryptophan fluorescence. Photochemistry, 63: $7-14$.

Garcia, C.A., A. Ahmadian, B. Gharizadeh, J. Lundeberg and M. Ronaghi et al., 2000. Mutation detection by pyrosequencing: Sequencing of exons 5-8 of the p53 tumour suppressor gene. Gene, 253: 249-257. PMID: 10940563

Gharizadeh, B., M. Kalantari, C.A. Garcia, B. Johansson and P. Nyren, 2001. Typing of human papillomavirus by pyrosequencing. Lab. Invest., 81: 673-679.

Gharizadeh, B., T. Nordstrom, A. Ahmadian, M. Ronaghi and P. Nyren, 2002. Anal Biochem. 2002. Long-read pyrosequencing using pure 2'deoxyadenosine-5'-O'-(1-thiotriphosphate) Spisomer. Anal. Biochem., 301: 82-90.

Gharizadeh, B., 2003. Method Development and Applications of Pyrosequencing Technology. 1st Edn., Stockholm, ISBN: 9172836105, pp: 64.

Gharizadeh, B., M. Kaller, P. Nyren, A. Andersson and M. Uhlen et al., 2003a. Viral and microbial genotyping by a combination of multiplex competitive hybridization and specific extension followed by hybridization to generic tag arrays. Nucl. Acids Res., 31: 146-146. DOI: 10.1093/nar/gng147

Gharizadeh, B., A. Ohlin, P. Molling, A. Backman and B. Amini et al., 2003b. Multiple group-specific sequencing primers for reliable and rapid DNA sequencing. Mol. Cell Probes, 17: 203-210. PMID: 12944124

Gharizadeh, B., M. Ghaderi, D. Donnelly, B. Amini and K.L. Wallin et al., 2003c. Multiple-primer DNA sequencing method. Electrophoresis, 24: 11451151. DOI: $10.1002 /$ elps.200390147
Gharizadeh, B., J. Eriksson, N. Nourizad, T. Nordstrom and P. Nyren, 2004. Improvements in pyrosequencing technology by employing sequenase polymerase. Anal. Biochem., 330: 272280. DOI: 10.1016/j.ab.2004.03.018

Gharizadeh, B., M. Oggionni, B. Zheng, E. Akom and N. Pourmand, 2005. Type-specific multiple sequencing primers: A novel strategy for reliable and rapid genotyping of human papillomaviruses by pyrosequencing technology. J. Mol. Diagn., 7: 198-205. PMID: 15858143

Gharizadeh, B., B. Zheng, M. Akhras, M. Ghaderi and O. Jejelowo, 2006. Sentinel-base DNA genotyping using multiple sequencing primers for high-risk human papillomaviruses. Mol. Cell Probes, 20: 230-238. DOI: 10.1016/j.mcp.2006.01.002

Gharizadeh, B., M. Ghaderi and P. Nyren, 2007. Pyrosequencing technology for short DNA sequencing and whole genome sequencing. Tech., 47: 129-132. DOI: 10.2142/biophys.47.129

Grahn, N., M. Olofsson, K. Ellnebo-Svedlund, H.J. Monstein and J. Jonasson, 2003. Identification of mixed bacterial DNA contamination in broad-range PCR amplification of $16 \mathrm{~S}$ rDNA V1 and V3 variable regions by pyrosequencing of cloned amplicons. FEMS Microbiol. Lett., 219: 87-91. DOI: $10.1016 / \mathrm{S} 0378-1097(02) 01190-4$

Hall, N., 2007. Advanced sequencing technologies and their wider impact in microbiology. J. Exp. Biol., 209: 1518-1525. DOI: $10.1242 /$ jeb.001370

Hyman, E.D., 1988. A new method of sequencing DNA. Anal. Biochem., 174: 423-436. DOI: 10.1016/0003-2697(88)90041-3

Jonasson, J., M. Olofsson and H.J. Monstein, 2002. Classification, identification and subtyping of bacteria based on pyrosequencing and signature matching of $16 \mathrm{~S}$ rDNA fragments. APMIS, 110: 263-272. DOI: $10.1034 /$ j.16000463.2002.100309.x

Karamohamed, S., J. Nilsson, K. Nourizad, M. Ronaghi and B. Pettersson et al., 1999. Production, purification and luminometric analysis of recombinant Saccharomyces cerevisiae MET3 adenosine triphosphate sulfurylase expressed in Escherichia coli. Protein Exp. Purif., 15: 381-388. PMID: 10092498

Khrapko, K.R., Y.P. Lysov, A.A. Khorlyn, V.V. Shick and V.L. Florentiev et al., 1989. An oligonucleotide hybridization approach to DNA sequencing. FEBS Lett., 256: 118-122. DOI: 10.1016/0014-5793(89)81730-2

Lahser, F.C., J. Wright-Minogue, A. Skelton and B.A. Malcolm, 2003. Quantitative estimation of viral fitness using pyrosequencing. Biotechniques, 34: 26-28. PMID: 12545532 
Lundin, A., C. Nilsson, M. Gerhard, D.I. Andersson and M. Krabbe et al., 2003. The NudA protein in the gastric pathogen Helicobacter pylori is an ubiquitous and constitutively expressed dinucleoside polyphosphate hydrolase. J. Biol. Chem., 278: 12574-12578. DOI: 10.1074/jbc.M212542200

Margulies, M.M., M. Egholm, W.E. Altman, S. Attiya and J.S. Bader et al., 2005. Genome sequencing in microfabricated high-density picolitre reactors. Nature, 437: 376-380. DOI: 10.1038/nature03959

Melamede, R.J., 1985. Automatable process for sequencing nucleotide. United States Patent 4863849.

Milan, D., J.T. Jeon, C. Looft, V. Amarger and A. Robic, 2000. A mutation in PRKAG3 associated with excess glycogen content in Pig Skeletal Muscle. Science, 288: 1248-1251. DOI: 10.1126/science.288.5469.1248

Monstein, H.J., S. Nikpour-Badr and J. Jonasson, 2001. Rapid molecular identification and subtyping of Helicobacter pylori by pyrosequencing of the $16 \mathrm{~S}$ rDNA variable V1 and V3 regions. FEMS Microbiol. Lett., 199: 103-107. DOI: 10.1016/S0378-1097(01)00171-9

Neve, B., P. Froguel, L. Corset, E. Vaillant and V. Vatin et al., 2002. Rapid SNP allele frequency determination in genomic DNA pools by pyrosequencing. Biotechniques, 32: 1138-1142. PMID: 12019787

Nordstrom, T., B. Gharizadeh, N. Pourmand, P. Nyren and M. Ronaghi, 2001. Method enabling fast partial sequencing of cDNA clones. Anal. Biochem., 292: 266-271. DOI: 10.1006/abio.2001.5094

Nordstrom, T., M. Ronaghi, L. Forsberg, U. Faire and R. Morgenstern et al., 2000. Direct analysis of single-nucleotide polymorphism on doublestranded DNA by pyrosequencing. Biotechnol. Applied Biochem., 31: 107-112. DOI: 10.1042/BA19990104

Nourizad N., M. Ehn, B. Gharizadeh, S. Hober and P. Nyren, 2003. Methylotrophic yeast Pichia pastoris as a host for production of ATPdiphosphohydrolase (apyrase) from potato tubers (Solanum tuberosum). Protein Exp. Purif., 27: 229237.

Nyren, P and A. Lundin, 1985. Enzymatic method for continuous monitoring of inorganic pyrophosphate synthesis. Anal. Biochem., 151: 504-509. DOI: 10.1016/0003-2697(85)90211-8
Nyren, P. and S.E. Skarpnack, 2001. Method of sequencing DNA based on the detection of the release of pyrophosphate and enzymatic nucleotide degradation. U.S. Patent 6258568.

O’Meara, D., K. Wilbe, T. Leitner, B. Hejdeman and J. Albert et al., 2001. Monitoring resistance to human immunodeficiency virus type 1 protease inhibitors by pyrosequencing. J. Clin. Microbiol., 39: 464473. DOI: 10.1128/JCM.39.2.464-473.2001

Ronaghi, M., 2000. Improved performance of pyrosequencing using single-stranded DNAbinding protein. Anal. Biochem., 286: 282-288. PMID: 11067751

Ronaghi, M., 2001. Pyrosequencing sheds light on DNA sequencing. Genome Res., 11: 3-11. DOI: 10.1101/gr.150601

Ronaghi, M., M. Nygren, J. Lundeberg and P. Nyren, 1999. Analyses of secondary structures in DNA by pyrosequencing. Anal. Biochem., 267: 65-71. DOI: 10.1006/abio.1998.2978

Ronaghi, M., M. Uhlen and P. Nyren, 1998. A sequencing method based on real-time pyrophosphate. Sci., 281: 363-365. DOI: 10.1126/science.281.5375.363

Ronaghi, M., S. Karamohamed, B. Pettersson, M. Uhlen and P. Nyren, 1996. Real-time DNA sequencing using detection of pyrophosphate release. Anal. Biochem., 242: 84-89. DOI: 10.1006/abio.1996.0432

Sanger, F., S. Nicklen and A.R. Coulson, 1977. DNA sequencing with chain-terminating inhibitors. Proc. Natl. Acad. Sci. USA., 74: 5463-5467.

Southern, E.M., 1989. Analysing polynucleotide sequences. US Patent no. WO/10977.

Sun, Y.Q., H.J. Monstein, L.E. Nilsson, F. Petersson and K. Borch, 2003. Profiling and identification of Eubacteria in the stomach of Mongolian gerbils with and without Helicobacter pylori infection. Helicobacter, 8: 149-157. DOI: 10.1046/j.15235378.2003.00136.x

Tarnberg, M., T. Jakobsson, J. Jonasson and U. Forsum, 2002. Identification of randomly selected colonies of lactobacilli from normal vaginal fluid by pyrosequencing of the $16 \mathrm{~S}$ rDNA variable $\mathrm{V} 1$ and V3 regions. APMIS, 110: 801-810. PMID: 12588421

Trama, J.P., E. Mordechai and M.E. Adelson, 2005. Detection of Aspergillus fumigatus and a mutation that confers reduced susceptibility to itraconazole and posaconazole by real-time PCR and pyrosequencing. J. Clin. Microbiol., 43: 906-908. DOI: 10.1128/JCM.43.2.906-908.2005 
Am. J. Biochem. \& Biotech., 8(1): 14-20, 2012

Unnerstad, H., H. Ericsson, A. Alderborn, W. Tham and M.L. Danielsson-Tham et al., 2001. Pyrosequencing as a method for grouping of Listeria monocytogenes strains on the basis of single-nucleotide polymorphisms in the inlB gene. Applied Environ. Microbiol., 67: 5339-5342. DOI: 10.1128/AEM.67.11.5339-5342.2001a
Uhlmann, K., A. Brinckmann, M.R. Toliat, H. Ritter and P. Nurnberg, 2002. Evaluation of a potential epigenetic biomarker by quantitative methyl-single nucleotide polymorphism analysis. Electrophoresis, 23: 4072-4079. DOI: 10.1002/elps. 200290023 